20

\title{
Изменение функциональной активности тромбоцитов при длительном световом воздействии в эксперименте
}

\author{
() О.В. Злобина, В.Ф. Киричук, С.С. Пахомий , А.Н. Иванов, А.Ю. Каретникова, Е.С. Терехина, \\ Н.В. Шляпников, И.О. Бугаева
}

Саратовский государственный медицинский университет им. В.И. Разумовского, 410012 Саратов, Россия

ฯ e-mail: spakhomy03@gmail.com

Поступила в редакцию 30.12.2020 г.

В окончательной редакции 03.02.2021 г.

Принята к публикации 26.02.2021 г.

\begin{abstract}
Изучено влияние интенсивного светового воздействия на агрегационную активность тромбоцитов белых крыс-самцов с использованием опытной модели освещения Light-Dark (18:6). Анализ агрегационной активности тромбоцитов проводили с помощью компьютеризированного анализатора агрегации 230LA „Biola“, используя методику B.А. Габбасова. Установлено, что при длительном световом воздействии в организме лабораторных животных происходит нарушение агрегационной активности, сопровождающееся ростом показателей кривой средневзвешенного радиуса тромбоцитов и параметров кривой светопропускания. Нарушение дневного режима в виде искусственного продления освещения вызывает увеличение агрегационной активности тромбоцитов и провоцирует развитие микроциркуляторных нарушений. Формирующиеся изменения в системе гемостаза нарастают пропорционально длительности эксперимента. Наиболее выраженные изменения в сосудисто-тромбоцитарном механизме гемостаза формируются на 21-е сутки эксперимента, что свидетельствует о развитии процессов дезадаптации с последующим истощением организма.
\end{abstract}

Ключевые слова: агрегация тромбоцитов, циркадные ритмы, световое воздействие, нарушения фотопериодизма, микроциркуляторные нарушения.

DOI: $10.21883 /$ OS.2021.06.50981.11-21

\section{Введение}

В современном мире человек все чаще находится в условиях ненормированного рабочего дня и регулярного вынужденного продления воздействия искусственного освещения в темное время суток $[1,2]$. Особенно актуально это для лиц, работающих сверхурочно и ночью, а также осуществляющих частые трансмередианные перелеты $[3,4]$. Смена временного режима и неравномерное чередование периодов сна и бодрствования индуцирует развитие как функциональных, так и структурных нарушений, значительно повышая риск развития различных патологий, включая ожирение, сахарный диабет, онкологические и сердечно-сосудистые заболевания $[5,6]$.

Патологическое рассогласование циркадианных ритмов (суточных и околосуточных) рассматривается как мощный стрессогенный фактор, индуцирующий развитие светового десинхроноза [7,8]. В условиях длительного светового воздействия происходит снижение синтеза мелатонина и развитие мощной стресс-реакции, сопровождающейся повышением концентрации адренокортикотропного гормона и катехоламинов в крови. Повышение уровня стрессогенных гормонов приводит к спазму сосудов и развитию феномена централизации кровотока, а уменьшение титра мелатонина в крови способствует увеличению функциональной активности тромбоцитов с нарушением микроциркуляции и гемокоагуляции. Расстройства ауторегуляторных механизмов при световой десинхронизации биологических функций влечет за собой нарушение кровообращения прежде всего в сосудах микроциркуляторного русла.

Степень выраженности функциональных и структурных нарушений зависит от длительности светового воздействия, мощности внешнего осциллятора и типа режима освещения. При исследовании на лабораторных животных было установлено, что полное „отключение“ внешнего ритмозадатчика и моделирование режима непрерывного освещения в лаборатории (модель LightLight) вызывает наиболее выраженные последствия для организма и сопровождается развитием признаков повреждения (дистрофических и некротических изменений) в паренхиматозных органах и увеличением агрегационной активности тромбоцитов в сосудах микроциркуляторного русла [9-11]. В работах [12-14] было показано, что длительное воздействие постоянного света снижает время бодрствования и вызывает у грызунов развитие ожирения и сахарного диабета 2-го типа.

Применение модели Light-Dark (12:12) с наличием тусклого освещения в темное время интенсивностью $5 \mathrm{lk}$ у крыс линии Wistar вызывало нарушение сна [1]. Относительно кратковременное нахождение (4-6 недель) лабораторных мышей в условиях 20-часового светлотемного цикла, состоящего из $10 \mathrm{~h}$ света и $10 \mathrm{~h}$ темноты (Light-Dark 10:10), вызывало нарушение метаболизма, увеличение веса и повышение концентрации в плазме крови лептина, инсулина и триглицеридов [15]. В ис- 
следовании [16] показано, что данные изменения в биохимическом составе крови лабораторных животных непосредственно связаны с изменением продолжительности и качества сна.

До настоящего времени остаются не изученными вопросы влияния удлиненного фотопериода освещения модели Light-Dark с чередованием светового и темнового режимов на кровоток в сосудах микроциркуляторного русла и способность тромбоцитов к агрегации. В связи с этим целью настоящего исследования явилось изучение влияния длительного светового воздействия (модели Light-Dark 18:6) на агрегационную активность тромбоцитов белых крыс в эксперименте.

\section{Материалы и методы}

Исследование выполнено на базах центральной научно-исследовательской лаборатории Саратовского ГМУ им. В.И. Разумовского и лаборатории гемостаза кафедры нормальной физиологии имени И.А. Чуевского. Эксперимент проводился на белых беспородных крысахсамцах, с массой $225 \pm 25 \mathrm{~g}$, с соблюдением международных этических норм Европейской конвенции защиты позвоночных животных для экспериментальных и других научных целей (Страсбург, 1986) и „International Guiding principles for Biomedical Research Involving Animals“ (2012), а также на основании рекомендаций комитета по этике ФГБОУ ВО Саратовский ГМУ им. В.И. Разумовского Минздрава РФ (протокол № 4 от 06.12.2016 г.). Лабораторные животные были распределены на 3 группы: две - опытные, одна - контрольная, в каждой группе по 12 особей.

Для оценки влияния удлиненного фотопериода экспериментальные животные подвергались искусственному световому воздействию с использованием дифференцированного подхода к чередованию светового и темнового режимов модели Light-Dark (18:6) в течение 10 и 21 суток (рис. 1). Модель Light-Dark предполагает $18 \mathrm{~h}$ непрерывного светового воздействия с интенсивностью освещения $500 \mathrm{lk}$ и $6 \mathrm{~h}$ режима темного времени. Временные периоды экспериментальной модели были выбраны на основании данных о стадийности развития стрессорных реакций в организме: 10-е сутки характеризуются развитием стадии общего адаптационного синдрома, 21-е сутки - развитием срыва адаптационных механизмов [17]. Эксперимент проводился в осенний период. Животные контрольной группы находились в условиях естественного фотопериода в течение 21 суток. Животные всех экспериментальных групп имели свободный доступ к воде и пище.

Исследование функциональной активности тромбоцитов проводили по методу 3.А. Габбасова и соавт. [18] с использованием компьютеризированного двухканального лазерного анализатора агрегации 230LA „Biola“ (НФП „Биола“, Россия), не позднее 3 h с момента забора крови. Забор крови производили пункцией из правых отделов сердца у животных, выведенных из эксперимента путем введения внутримышечно комбинации Телазола (Zoetis Inc, CША) в дозе $0.1 \mathrm{ml} / \mathrm{kg}$ и Ксиланита (НитаФарм, Россия) в дозе $0.1 \mathrm{ml} / \mathrm{kg}$. В качестве антикоагулянта использовался $0.2 \%$ раствор цитрата натрия в соотношении 9:1.

Лазерный анализатор агрегации исследует процесс агрегации тромбоцитов на основании регистрации изменений светопропускания обогащенной тромбоцитами плазмы (турбидометрический метод) и флуктуаций светопропускания плазмы, вызванных случайным изменением количества и размера тромбоцитов и их агрегатов в тонком лазерном оптическом канале. Относительная дисперсия таких флуктуаций пропорциональна среднему размеру агрегатов и используется для исследования кинетики агрегации. Калибровку прибора проводили для каждого животного путем регистрации светопропускания бедной тромбоцитами плазмы (результат принимали за $100 \%$ ) и обогащенной тромбоцитами плазмы с добавлением $10 \mathrm{mcl} 100 \mathrm{mM}$ раствора ЭДТА (полученные данные оценивали в качестве 0). Средневзвешенный радиус обогащенной тромбоцитами плазмы принимался за 1 условную единицу. Измерение агрегации тромбоцитов в обогащенной тромбоцитами плазме объемом $300 \mathrm{mcl}$ проводилось при соблюдении условий термостатирования $37^{\circ} \mathrm{C}$ в рабочем гнезде агрегометра и скорости перемешивания $800 \mathrm{rpm}$ [19]. Регистрация процесса агрегации тромбоцитов осуществлялась на основании данных кривой светопропускания и кривой средневзвешенного радиуса, отображаемых на экране монитора компьютера, сопряженного с агрегометром.

Динамику изменений агрегационной активности кровяных пластинок оценивали с помощью показателей кривой средневзвешенного радиуса тромбоцитов и кривой светопропускания. В качестве индуктора агрегации тромбоцитов использовался раствор АДФ (НПО „РЕНАМ“, Россия) в концентрации $2.5 \mathrm{mmol} / \mathrm{ml}$.

Статистическую обработку данных проводили с использованием пакета программ „STATISTICA 10.0“ (StatSoft ${ }^{\circledR}$, США). В случае отличия распределения значений в выборке от нормального вычисляли медиану и квартили. При оценке значимости различий использовался U-критерий Манна-Уитни. Статистически значимыми считали изменения при $p<0.05$.

\section{Результаты и обсуждение}

У лабораторных животных, находившихся в условиях длительного светового воздействия, отмечен рост показателей кривой средневзвешенного радиуса тромбоцитов: повышение максимального размера образующихся тромбоцитарных агрегатов с увеличением максимальной скорости их образования и времени достижения ими наибольшего размера (рис. 2,3). 


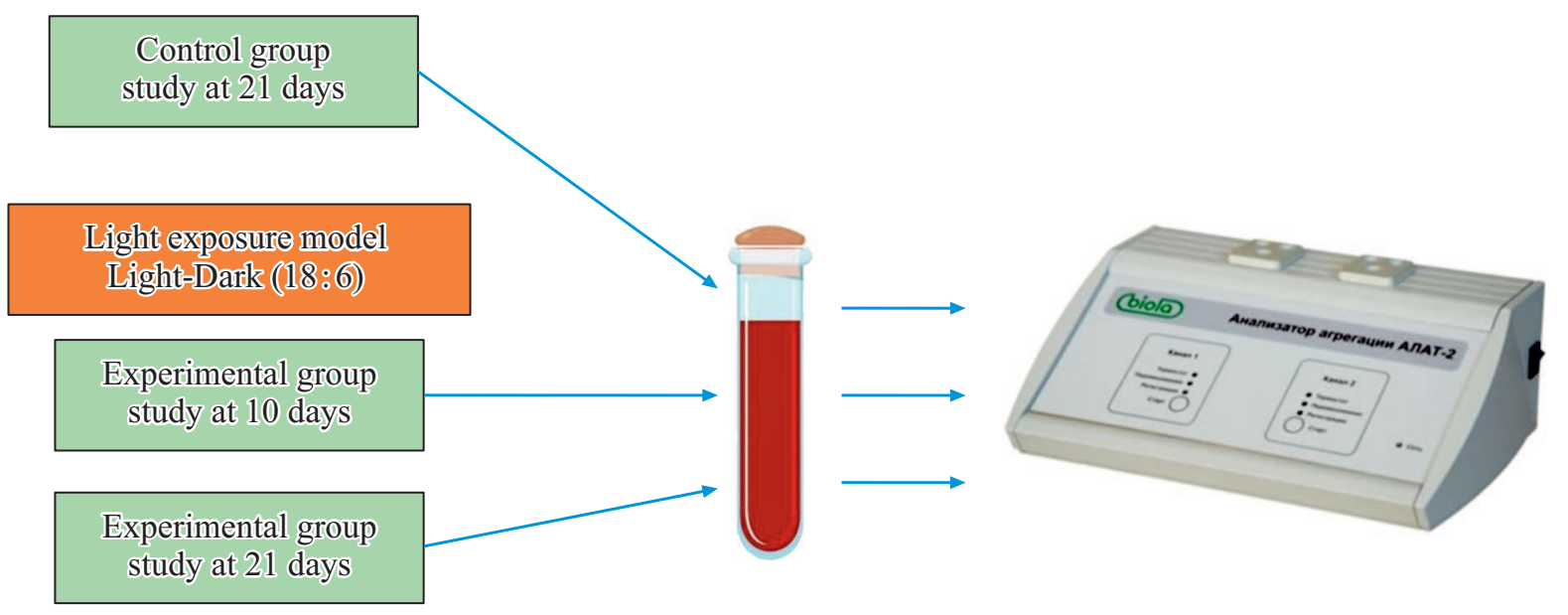

Рис. 1. Экспериментальная модель светового воздействия режима Light-Dark (18:6).
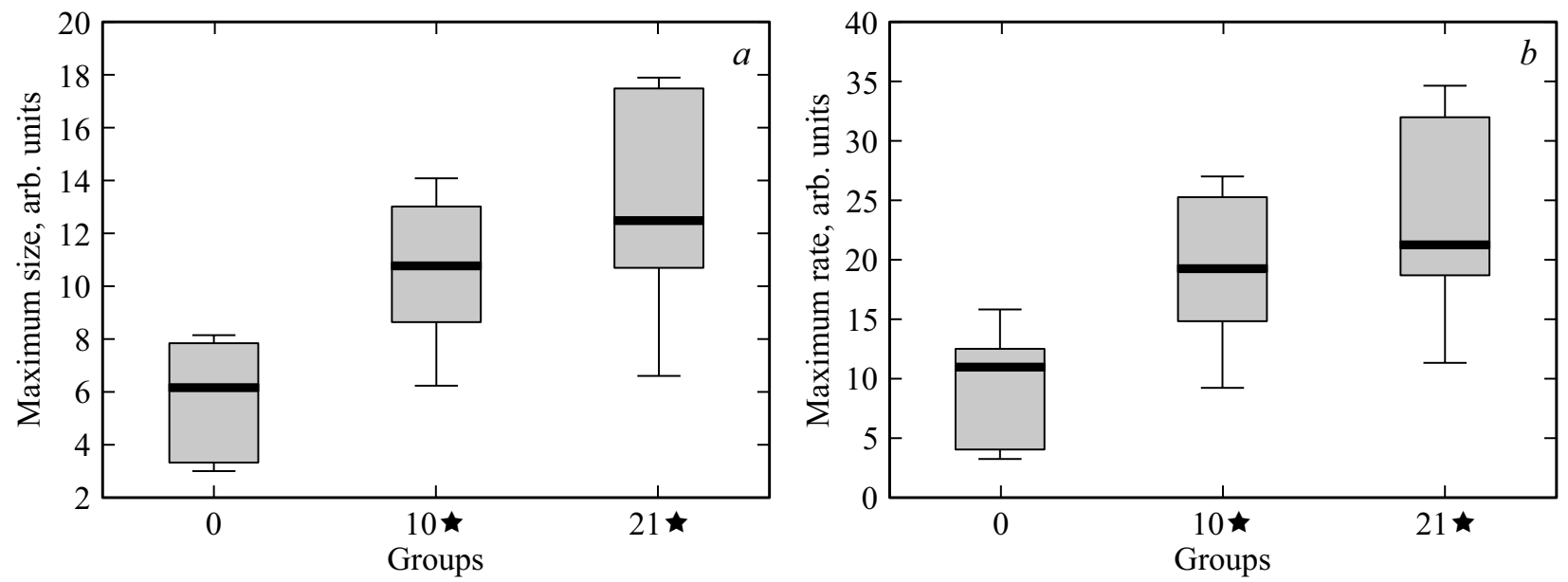

Рис. 2. (a) Сравнительный максимальный размер образующихся тромбоцитарных агрегатов; $(b)$ относительная максимальная скорость образования наибольших тромбоцитарных агрегатов.
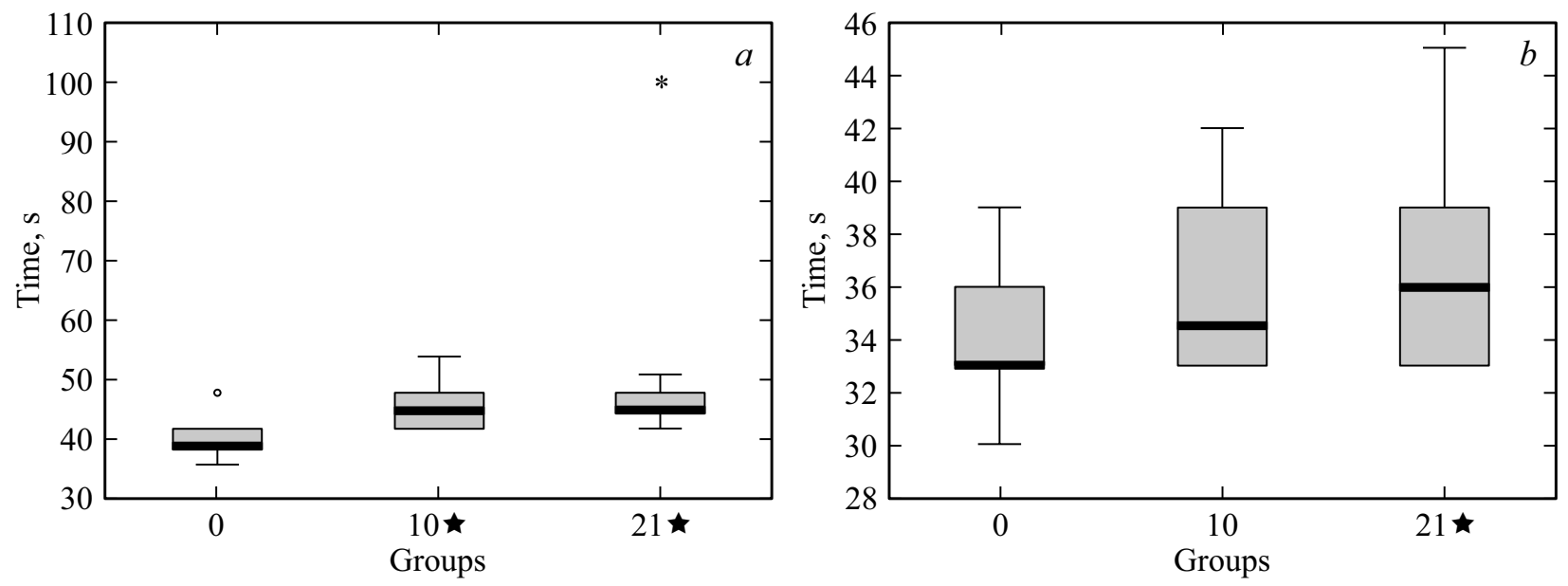

Рис. 3. (a) Время достижения максимального размера образующихся тромбоцитарных агрегатов; $(b)$ время достижения максимальной скорости образования наибольших тромбоцитарных агрегатов. 

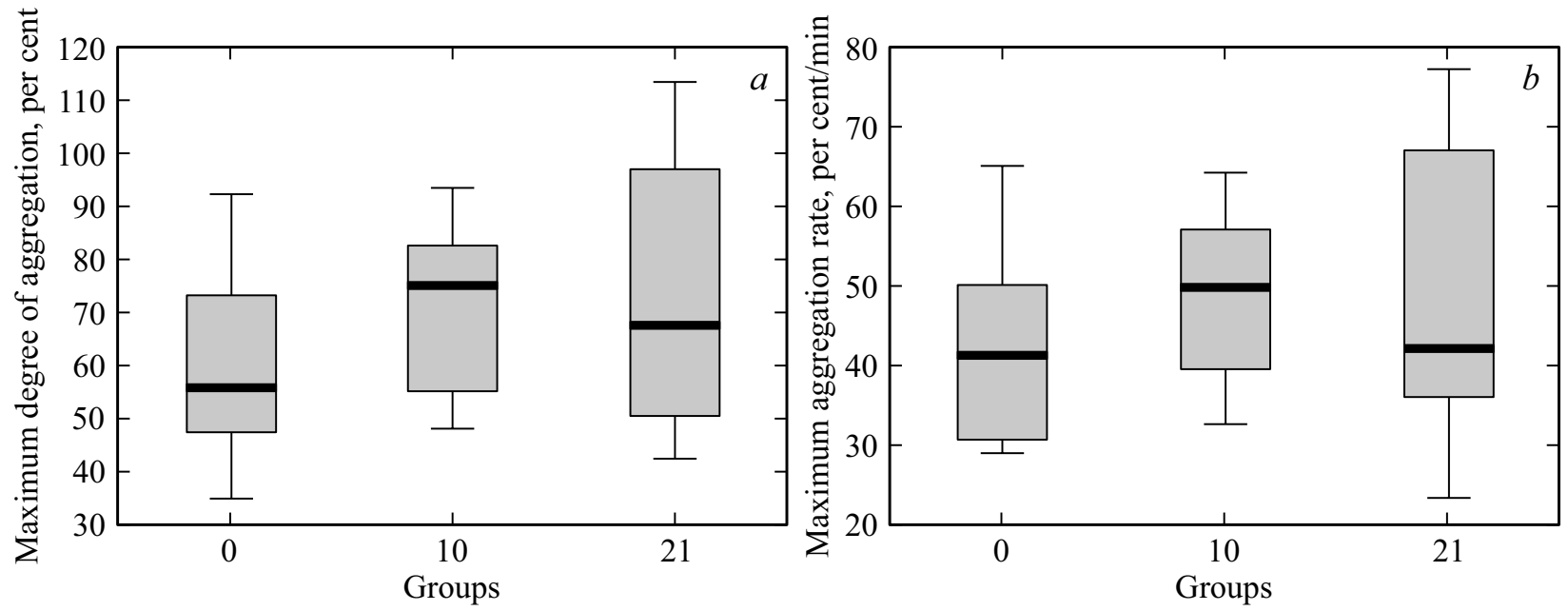

Pис. 4. (a) Максимальная степень агрегации; (b) максимальная скорость агрегации.
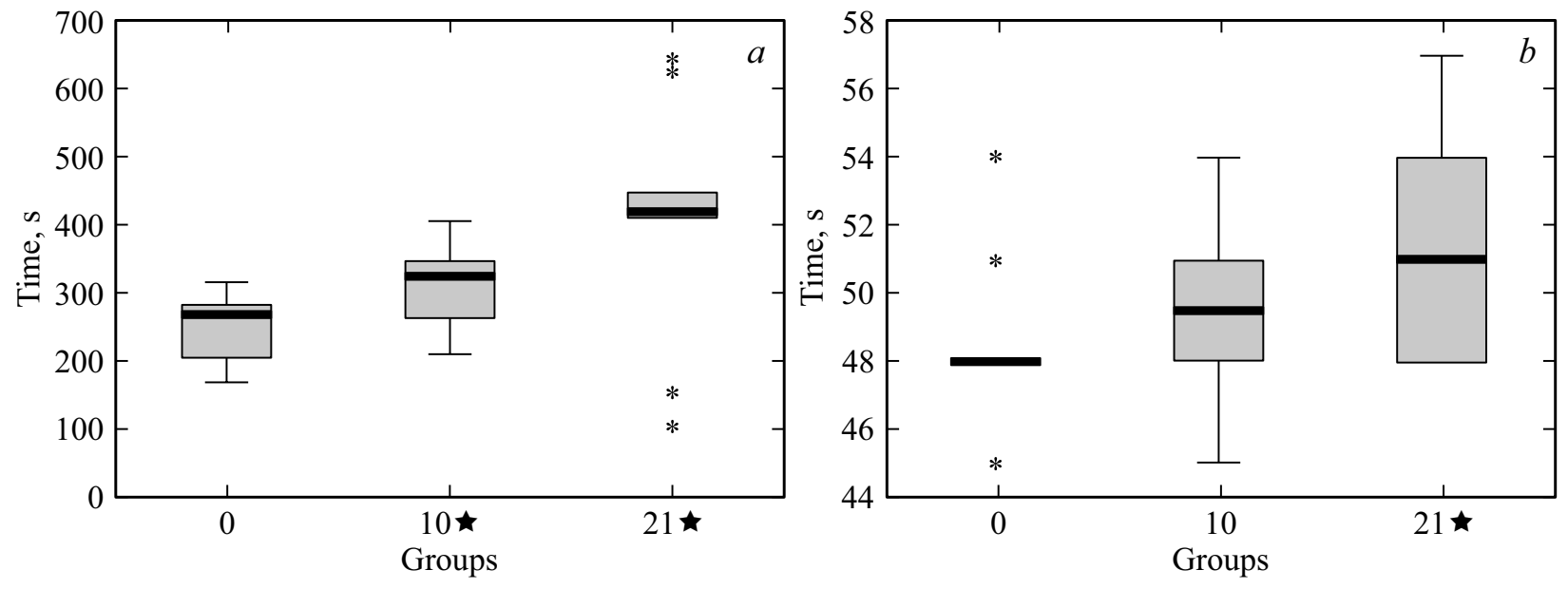

Рис. 5. (a) Время достижения максимальной степени агрегации; $(b)$ время достижения максимальной скорости агрегации.

На 10-е сутки эксперимента максимальный размер образующихся тромбоцитарных агрегатов определялся на уровне $10.8[9.1 ; 12.9]$, максимальная скорость образования наибольших тромбоцитарных агрегатов $19.4[15.9 ; 24.9]$, что превышало показатели в контрольной группе животных на 74\%. Увеличение длительности светового воздействия до 21-х суток сопровождалось дальнейшим ростом данных показателей: максимальный размер образующихся тромбоцитарных агрегатов составил 12.5 [10.6; 12.6], максимальная скорость образования наибольших тромбоцитарных агрегатов $21.4[18.8 ; 22]$, что почти в 2 раза превысило значения в контрольной группе. Время достижения максимального размера образующихся тромбоцитарных агрегатов на 10 -е и на 21 -е сутки эксперимента увеличилось на $15 \%$ и определялось на уровне $45[42 ; 48]$ и $45[44.2 ; 48.7]$ соответственно. Время достижения максимальной скорости образующихся тромбоцитарных агрегатов достоверно изменялось только на 21-е сутки эксперимента и составило 36 [33;37], при контрольных значениях $33[33 ; 35]$.

Длительное световое воздействие сопровождалось также увеличением показателей кривой светопропускания у лабораторных животных: повышением скорости и времени достижения максимальной степени агрегации (рис. 4,5).

На 10-е сутки эксперимента отмечалось нарастание скорости достижения максимальной степени агрегации до 327 [284.8;348.8], что превысило показатели в контрольной группе на $22 \%$. Наблюдалась также тенденция к увеличению показателей максимальной степени агрегации до 49.9 [42.2; 55.2] и максимальной скорости агрегации до $75.1[57.1 ; 80]$.

Увеличение длительности светового воздействия до 21-х суток сопровождалось дальнейшим нарастанием ряда показателей кривой светопропускания. Скорость достижения максимальной степени агрегации статистически значимо возросла на $58 \%$ относительно контроль- 
ных значений и составила 421 [355; 492]. Обращает на себя внимание тенденция к снижению показателей максимальной степени агрегации и максимальной скорости агрегации на $15 \%$ и $10 \%$ соответственно по сравнению со значениями, полученными в группе животных на 10-е сутки эксперимента.

Результаты проведенного исследования показали, что непрерывное световое воздействие в течение $18 \mathrm{~h}$ вызывает нарушение функционального статуса тромбоцитов с усилением их агрегационной активности. Выраженность изменений агрегационной активности тромбоцитов нарастает с увеличением длительности эксперимента и достигает наибольших значений на 21-е сутки светового воздействия.

Агрегация тромбоцитов является сложным процессом, в котором участвуют гликопротеиновые рецепторы, проагреганты (тромбоксан $\mathrm{A}_{2}$, тромбин, адреналин, колаген и другие) и антиагреганты (простациклины, оксид азота). Увеличение максимального размера образующихся тромбоцитарных агрегатов и повышение скорости их образования свидетельствует о развитии гиперагрегационного синдрома, формирующегося в результате дестабилизации мембран тромбоцитов в условиях окислительного стресса [20]. Активированные тромбоциты начинают секретировать большое количество тромбоксана $\mathrm{A}_{2}$, который, в свою очередь, стимулирует к адгезии и агрегации новые тромбоциты [21]. Формирующаяся реакция в сосудах микроциркуляторного русла развивается на фоне снижения синтеза гормона мелатонина, играющего ключевую роль в регуляции циркадных ритмов. При недостаточной продукции мелатонина происходит нарушение цикла „сон-бодрствование“, что является провоцирующим фактором в развитии стрессовой реакции в организме. При этом выброс клетками мозгового вещества надпочечников катехоламинов в ответ на возбуждение рецепторов симпатоадреналовой системы также усиливает агрегационную активность тромбоцитов [22].

Повышение адгезивной и агрегационной активности тромбоцитов приводит к образованию тромбоцитарных агрегатов в сосудах микроциркуляторного русла [22,23]. В результате возникают условия, способствующие формированию тромбов и, как следствие, развитию окклюзии сосудов капиллярного типа, что ведёт к формированию зоны ишемии и некроза и является одной из причин развития цереброваскулярных заболеваний и инфаркта миокарда [22,24].

\section{Заключение}

В результате настоящего исследования установлено, что длительное световое воздействие оказывает негативное влияние на тромбоцитарное звено гемостаза. Выраженность изменений функциональной активности тромбоцитов нарастает с увеличением длительности эксперимента. У животных на 10-е сутки пребывания в условиях световой депривации наблюдается существенное нарастание тромбоцитарной активности, что свидетельствует о развитии процессов срочной адаптации организма. На 21-е сутки эксперимента формируются еще более выраженные изменения в сосудистотромбоцитарном механизме гемостаза, что свидетельствует о развитии процессов дезадаптации с последующим истощением организма и формированием недостаточности компенсаторных механизмов. Таким образом, длительное световое воздействие является мощным стрессогенным фактором, которое вызывает увеличение агрегационной активности тромбоцитов и провоцирует развитие микроциркуляторных нарушений.

\section{Соблюдение этических стандартов}

Все применимые международные, национальные и/или институциональные принципы ухода и использования животных были соблюдены.

\section{Финансирование работы}

Работа выполнена в рамках государственного задания ФГБОУ ВО Саратовский ГМУ им. В.И. Разумовского Министерства здравоохранения РФ по теме „Разработка математической модели для оценки скорости трансформации функциональных изменений в целостном организме при световом десинхронозе в необратимые морфологические изменения органов-мишеней в эксперименте“.

\section{Конфликт интересов}

Авторы заявляют, что у них нет конфликта интересов.

\section{Список литературы}

[1] Stenvers D.J., van Dorp R., Foppen E., Mendoza J., Opperhuizen A.-L., Fliers E., Bisschop P.H., Meijer J.H., Kalsbeek A., Deboer T. // Sci. Rep. 2016. V. 6. P. 35662. doi 10.1038/srep35662

[2] Cho Y., Ryu S.H., Lee B.R., Kim K.H., Lee E., Choi J. // Chronobiol. Internat. 2015. V. 32. N 9. P. 1294-1310.

[3] Cedernaes J., Waldeck N., Bass J. // Genes. Dev. 2019. V. 33. N 17-18. P. 1136-1158. doi 10.1101/gad.328633.119

[4] Koch C.E., Leinweber B., Drengberg B.C. et al. // Neurobiol Stress. 2017. V. 6. P. 57-67. doi 10.1016/j.ynstr.2016.09.001

[5] Early J.O., Curtis A.M. // Seminars in Immunology, Immunometabolism 2016. V. 28. N 5. P. 478-490. doi 10.1016/j.smim.2016.10.006

[6] Анисимов В.Н., Виноградова И.А., Букалев А.В. и др. // Вопр. онкол. 2014. Т. 60. № 2. С. 15-27.

[7] Зарипов А.А., Янович К.В., Потапов Р.В., Корнилова А.A. // Соврем. пробл. науки и образования. 2015. № 3. C. 25-29.

[8] Журкин К.И., Злобина О.В., Иванов А.Н., Бугаева И.О. $u$ дp. // Тромбоз, гемостаз и реология. 2016. № $3(67)$. C. 164-166. 
[9] Злобина О.В., Пахомий С.С., Бугаева И.О., Маслякова Г.Н., Иванов А.Н. // Вестник новых медицинских технологий. Электронное издание. 2018. № 5. С. 245-249.

[10] Терешкина Н.Е., Злобина О.В., Иванов А.Н., Долгов А.А. // Регионарное кровообращение и микроциркуляция. 2018. № 3 (67). C. 129-134. doi 10.24884/1682-6655-2018-17-3129-134

[11] Злобина О.В., Бугаева И.О., Пахомий С.С., Иванов А.Н., Слюсаренко Ю.А., Усольцева Е.Д. // Вестник новых медицинских технологий. Электронное издание. 2018. № 5. C. 250-254.

[12] Fonken L.K. et al. // PNAS. 2010. N 107. P. 18664-18669.

[13] Coomans C.P. et al. // FASEB J. 2013. N 27. P. 1721-1732.

[14] Casiraghi L.P., Alzamendi A., Giovambattista A., Chiesa1 J., Golombek A.D. // Physiological Reports. 2016. V. 4. N 8. E 12743. doi 10.14814/phy2.12743

[15] Karatsoreos I.N., Bhagat S., Bloss E.B., Morrison J.H., McEwen B.S. // PNAS. 2011. N 108. P. 1657-1662. doi 10.1073/pnas.1018375108

[16] Phillips D.J., Savenkova M.I., Karatsoreos I.N. // Brain, Behavior, and Immunity. 2015. N 47. P. 14-23. doi 10.1016/j.bbi.2014.12.008

[17] Морозов В.Н., Хадарцев А.А. // Вестник новых медицинских технологий. 2010. № 1. С. 15-17.

[18] Габбасов З.А., Попов Е.Г., Гаврилов И.Ю., Позин Е.Я., Маркосян Р.А. // Лабораторное дело. 1989. № 10. С. 15-18.

[19] Панюшкин В.В., Рожккова Е.А., Турова Е.А., Гозулов А.С., Сейбулла Р.Д. // Вест. спорт. науки. 2013. № 2. С. 25-30.

[20] Киричук В.Ф., Романова В.М., Злобина О.В., Бугаева И.О., Каретникова А.Ю., Терехина Е.С., Шляпников Н.В. // Сибирский научный медицинский журнал. 2020. T. 40. № 3. C. 21-27. doi 10.15372/SSMJ20200303

[21] Chen H. // Prostaglandins \& Other Lipid Mediators. 2018. V. 134. C. 32-37.

[22] Костенко Е.В., Маневич Т.М., Разумов Н.А. // Лечебное дело. 2013. Т. 17. № 2. С. 104-116.

[23] Поленов С.A. // Регионарное кровообращение и микроциркуляция. 2008. № 1. С. 5-19.

[24] Poredos P., Jezovnik M.K. // Angiology. 2017. V. 7. N 69. P. 564-567. 